Int. J. Electrochem. Sci., 14 (2019) 9337 - 9346

\title{
Silver Nanoparticles/Carboxylic Short-Chain Multi-Wall Carbon Nanotubes as Electrochemical Sensor for Ultrasensitive Detection of Chloramphenicol in Food
}

\author{
Panpan Zhang ${ }^{1}$, Nana Zhang ${ }^{1}$, Lijun Jing ${ }^{1}$, Bobo Hu ${ }^{1}$, Xiaodi Yang ${ }^{1, *}$, Xiaoling Ma ${ }^{2, *}$ \\ ${ }^{1}$ Jiangsu Collaborative Innovation Center of Biomedical Functional Materials, Jiangsu Key Laboratory \\ of Biomedical Materials, College of Chemistry and Materials Science, Nanjing Normal University, \\ Nanjing 210023, China \\ ${ }^{2}$ Obstetrics and Gynecology Hospital Affiliated to Nanjing Medical University, Nanjing 210004, \\ China \\ *E-mail: Yangxiaodi@njnu.edu.cn, maxiaolingpfk@126.com
}

doi: $10.20964 / 2019.09 .69$

Received: 8 May 2019 / Accepted: 4 July 2019 / Published: 5 August 2019

This research developed a novel electrochemical sensor for determination of chloramphenicol (CAP) in aqueous solutions. The working electrode was fabricated by carboxylic short-chain multi-wall carbon nanotubes (Short-MWNTs-COOH) and silver (Ag) nanoparticle based on glass carbon electrode (GCE). Scanning electron microscope (SEM) and electrochemical impedance spectroscopy (EIS) confirmed that Ag nanoparticle had been successfully electrodeposited onto the modified electrode. Then, some experimental parameters such as $\mathrm{pH}$, scan rate, deposition potential and time were optimized by cyclic voltammetry (CV) and linear sweep stripping voltammetry (LSSV). Under the optimized conditions satisfactory results attained for detection of CAP in the concentration range of 0.3-229 $\mu \mathrm{M}$ and with the detection limit ( $\mathrm{LOD}, \mathrm{S} / \mathrm{N}=3$ ) of $0.049 \mu \mathrm{M}$. This new electrochemical sensor showed many advantages like easy operation, low cost, and high sensitivity, which enables successful determination of CAP in real samples.

Keywords: Chloramphenicol; Silver Nanoparticle; Carboxylic Short-Chain Multi-Wall Carbon Nanotubes; Electrochemical Sensor.

\section{$\underline{\text { FULL TEXT }}$}

(C) 2019 The Authors. Published by ESG (www.electrochemsci.org). This article is an open access article distributed under the terms and conditions of the Creative Commons Attribution license (http://creativecommons.org/licenses/by/4.0/). 